http://jmscr.igmpublication.org/home/

ISSN (e)-2347-176x ISSN (p) 2455-0450

crossref DOI: https://dx.doi.org/10.18535/jmscr/v9i11.09

\title{
Estimation and Evaluation of Micronutrients and Vitamins Intake during
} Pregnancy

\author{
Authors \\ Dr Maleka Sultana ${ }^{1 *}$, Prof. Dr Md. Nurul Amin², Prof. Nizamul Hoque Bhuiyan ${ }^{3}$ \\ ${ }^{1}$ M.B.B.S. CMU, HMO (DMC), MPhil (DU), Dhaka, Bangladesh \\ ${ }^{2}$ Professor, Applied Chemistry and Chemical Engineering (ACCE), University of Dhaka \\ Dhaka, Bangladesh \\ ${ }^{3}$ Professor, Institute of Nutrition and Food Science (INFS), University of Dhaka, Dhaka, Bangladesh \\ *Corresponding Author \\ Dr Maleka Sultana
}

HMO, Department of Obstetrics and Gynecology, DMC

\begin{abstract}
Background: Iron deficiency anemia, folic acid deficiency, and calcium deficiency during pregnancy can lead to adverse outcomes for both the mother and the infant in developing countries. Preventive measure before and during pregnancy can control the rate of maternal and child mortality and morbidity.

Objective: The purpose of the current research work was to find out the prevalence and outcomes of Iron deficiency anemia, folate deficiency, and Calcium deficiency during as well as the steps to prevent and control them.
\end{abstract}

Method: A whole of 50 blood trials (samples) of pregnant women were drawn into EDTA tubes from December,2019 to February,2020, from the Dhaka Medical College Hospital of Dhaka during the visits of the pregnant women to the Obstetrics \&amp; Gynaecology Department by using Sysmex XN-2000.

Result: Among 50 pregnant women, total 13(26\%) pregnant women had moderate iron deficiency anemia, $5(10 \%)$ pregnant had severe iron deficiency anemia, and total $32(64 \%)$ pregnant women had mild iron deficiency anemia during pregnancy, it is also shown from the result that, total 32(64\%) pregnant women had mild folate deficiency anemia, 13(26\%) pregnant women had moderate folate deficiency anemia, and total $5(10 \%)$ pregnant women had severe folate deficiency anemia. and total 38(76\%) pregnant women had normal calcium level and total 12(24\%) pregnant had hypocalcemia or Calcium deficiency.

Conclusion: Iron deficiency, folic acid deficiency and calcium deficiency during pregnancy lead to potential threats to the mothers such as miscarriage, pre-eclampsia, hemorrhage. pregnancy induced hypertension (PIH) and also brings out negative outcomes to the infants such as prematurity, low birth weight, growth retardation, cleft lip, cleft palate and neural tube defects. Increasing awareness, proper diagnosis and management of iron, folic acid, calcium deficiency during pregnancy will fill the nutritional gap and control the major causes of mortality and morbidity and poor maternal and fetal outcomes of pregnancy in Bangladesh.

Keywords: Anemia, iron deficiency anemia in pregnancy, folic acid deficiency in pregnancy, hypocalcemia in pregnancy, Dhaka Medical College, Hospital, Bangladesh. 


\section{Introduction}

Globally, maternal anemia increases the risk of pre-term delivery and low birth weight, and iron deficiency anemia underlies 115,000 maternal deaths and 591,000 perinatal deaths each year. ${ }^{1}$ According to the Bangladesh Demographic and Health Survey- BDHS in 2011, approximately 49.6\%(one-half) pregnant women and $48 \%$ of lactating mothers are anaemic. ${ }^{2}$ Anaemia is recognized as a major public health problem in Bangladesh, ${ }^{3}$ affecting nearly half of the pregnant women in the country ${ }^{4}$ and iron deficiency is the major cause of anaemia in the Bangladeshi population. ${ }^{\mathbf{5}}$ Low- calcium diet or hypocalcemia during pregnancy is associated with significant increases in arterial BP, systemic and uterine vascular resistance, proteinuria, and significant reductions in cardiac output and UBF (uterine blood flow), these changes are reported as Pregnancy Induced Hypertension (PIH). ${ }^{\mathbf{6}}$ Pregnancy Induced Hypertension (PIH) triggers preeclampsia which is associated with high perinatal morbidity and mortality. ${ }^{7}$ Preeclampsia is associated with an increased incidence of intrauterine growth retardation as high as $40 \% .^{8}$ In Bangladesh, a high prevalence of Folic acid deficiency during pregnancy exists. ${ }^{9}$ Folic acid deficiencies during pregnancy can lead to neural tube defect (NTD), congenital heart disease and oral clefts (cleft lip, cleft palate), and possibly preterm birth. ${ }^{10-13}$

\section{Methods and Materials}

Study Place: Ward no-212, Obstetrics \&amp; Gynaecology Department, Dhaka Medical College Hospital, Dhaka.

Study Population: A whole of 50 blood samples of pregnant women were collected into EDTA tubes by using Sysmex XN-2000 from December, 2019 to February, 2020, from the Dhaka Medical College Hospital of Dhaka during the visits of the pregnant women to the Obstetrics \& Gynaecology Department.

Statistical Analysis: Collected data were analyzed by using SPSS version 22.0.
Table 1: Blood Collection

\begin{tabular}{|c|c|c|}
\hline Trimester & $\begin{array}{l}\text { Number of Pregnant } \\
\text { mother } \\
\text { Samples collection }\end{array}$ & $\begin{array}{l}\text { Time Period under sample } \\
\text { collected }\end{array}$ \\
\hline \multirow[t]{3}{*}{$1 \mathrm{st}$} & \multirow[t]{3}{*}{23} & December'2019 - 9sample \\
\hline & & January'2020 - 6sample \\
\hline & & February’2020 - 8sample \\
\hline \multirow[t]{3}{*}{2 nd } & \multirow[t]{3}{*}{13} & December'2019 - 4sample \\
\hline & & January’2020 - 5sample \\
\hline & & February’2020 - 4sample \\
\hline \multirow[t]{3}{*}{$3 r d$} & \multirow[t]{3}{*}{14} & December'2019 - 6sample \\
\hline & & January’2020 - 3sample \\
\hline & & February’2020 - 5sample \\
\hline Total & 50 & $100 \%$ \\
\hline
\end{tabular}

The first trimester yielded 23 pregnant womens blood samples, the second trimester yielded 13 pregnant Women's blood samples, and the third trimester yielded 14 pregnant womens blood samples. 19 pregnant mothers blood samples were taken in December 2019, 14 pregnant mother's blood sample were collected on January 2020 and 17 pregnant women's blood samples were collected on February 2020. During the month of December 2019, 9 blood samples were taken from pregnant women in their first trimester, 4 blood samples from pregnant women in their second trimester, and 6 blood samples from pregnant women in their third trimester. During 2020, 6 blood samples were taken from pregnant women in their first trimester, 5 blood samples from pregnant women in their second trimester, and 3 blood samples from pregnant women in their third trimester. During February 2020, 8 blood samples were taken from pregnant women in their first trimester, 4 from pregnant women in their second trimester, and 5 from pregnant women in their third trimester.

Table 2: Pregnancywith3trimesterstimeduration

\begin{tabular}{|l|c|c|}
\hline Trimesters & $\begin{array}{c}\text { Time periods (in } \\
\text { months) }\end{array}$ & $\begin{array}{c}\text { Time periods (in } \\
\text { weeks) }\end{array}$ \\
\hline 1 st & $1-3$ & $1-12$ \\
\hline 2nd & $4-6$ & $13-26$ \\
\hline 3rd & $7-9$ & $27-70$ \\
\hline
\end{tabular}

\section{Results}

Out of 50 pregnant women, it is shown from the result that, Total $32(64 \%)$ pregnant women's $\mathrm{Hb}$ level was in between $10-11 \mathrm{mg} / \mathrm{dl}$ and Serum Iron 
Level Women 40-50 $\mu \mathrm{g} / \mathrm{dl}$, which refers to mild iron deficiency anemia.

Total 13(26\%) pregnant women's $\mathrm{Hb}$ level was in between 7-10 $\mathrm{mg} / \mathrm{dl}$ and Serum Iron Level Women $30-40 \mu \mathrm{g} / \mathrm{dl}$, which refers to moderate iron deficiency anemia. Total 5(10\%) pregnant women's $\mathrm{Hb}$ level was in between \& $1 \mathrm{t} ; 7 \mathrm{mg} / \mathrm{dl}$ and Serum Iron Level Women \& $1 \mathrm{t} ; 30 \mu \mathrm{g} / \mathrm{dl}$, which refers to severe iron deficiency anemia.

Table1: Mild, moderate, severe iron deficiency anemia of pregnant mothers $(\mathrm{N}=50)$

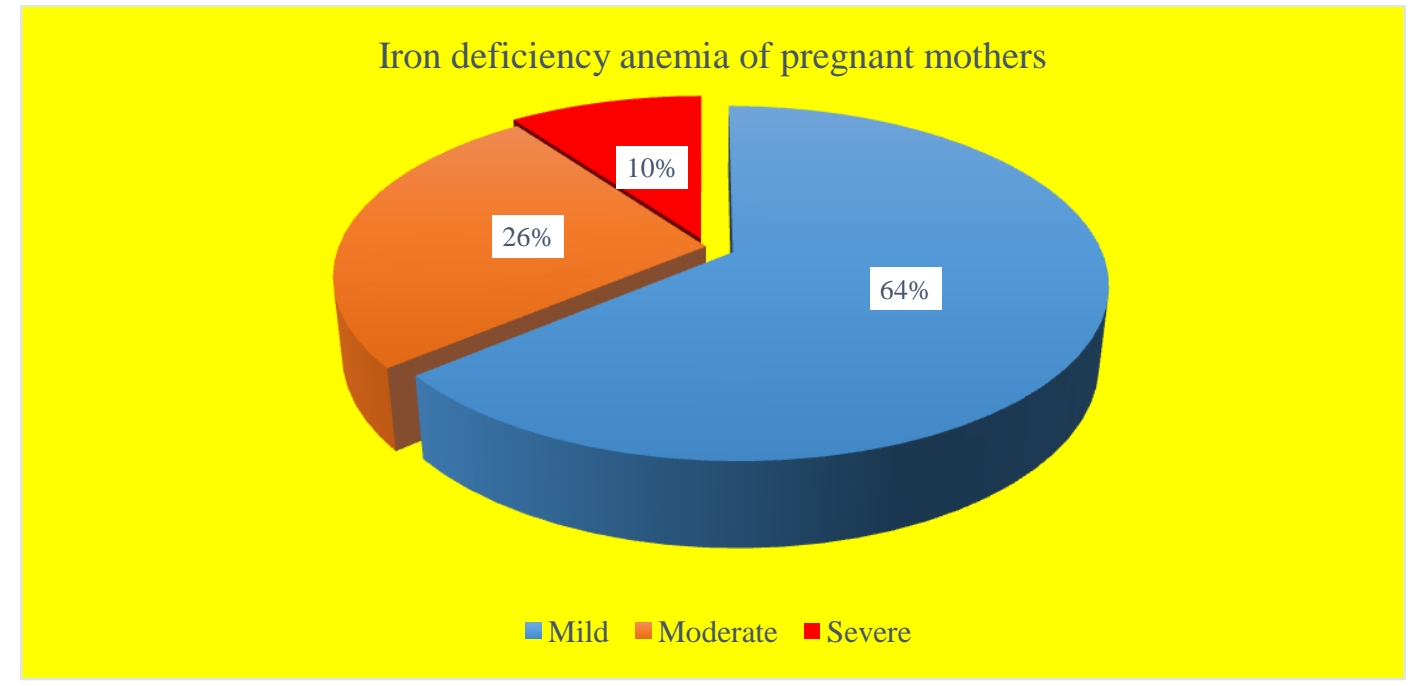

Figure: I Iron Deficiency Anemia of Pregnant Mothers (N=50)

Figure I showed that, 32(64\%) pregnant women's Serum Folic acid level was in between 3.0-4.0 $\mu \mathrm{g} / \mathrm{L}$, which refers to mild Folate deficiency anemia. 13(26\%) pregnant women's Serum Folic acid level was in between 2.0-3.0 $\mu \mathrm{g} / \mathrm{L}$ which refers to moderate Folate deficiency anemia. $5(10 \%)$ pregnant women's Serum Folic acid level was in between 1.0-2.0 $\mu \mathrm{g} / \mathrm{L}$, which refers to severe Folate deficiency anemia.

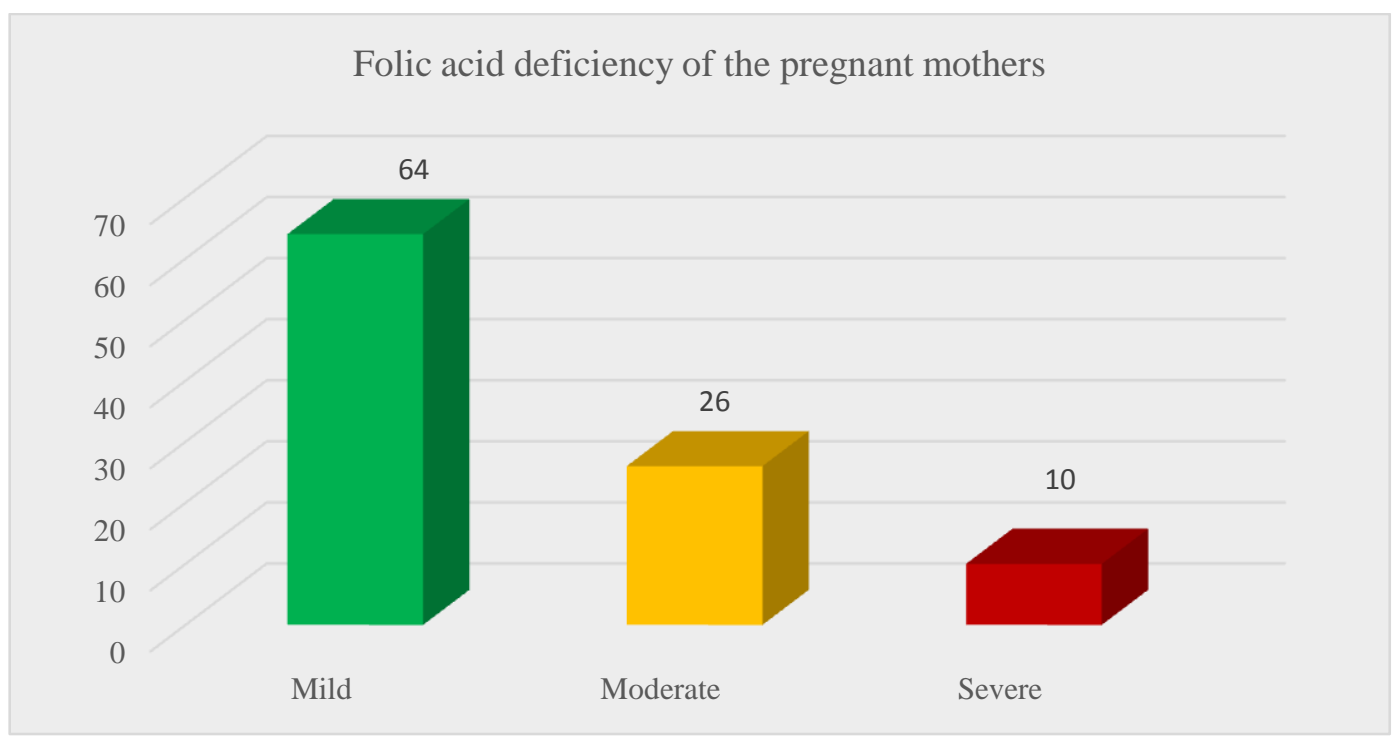

Figure: II Folic Acid Deficiency of Pregnant Mothers ( $\mathrm{N}=50)$

Figure II showed that, 32(64\%) pregnant women's serum Folic acid level was in between 3.0-4.0 $\mu \mathrm{g} / \mathrm{L}$, which referred to mild Folate deficiency anemia. 13(26\%) pregnant women's Serum Folic acid level was in between 2.0-3.0 $\mu \mathrm{g} / \mathrm{L}$ which referred to moderate Folate deficiency anemia. $5(10 \%)$ pregnant women's serum Folic acid level was in between 1.0-2.0 $\mu \mathrm{g} / \mathrm{L}$, which refers to severe Folate deficiency anemia. 


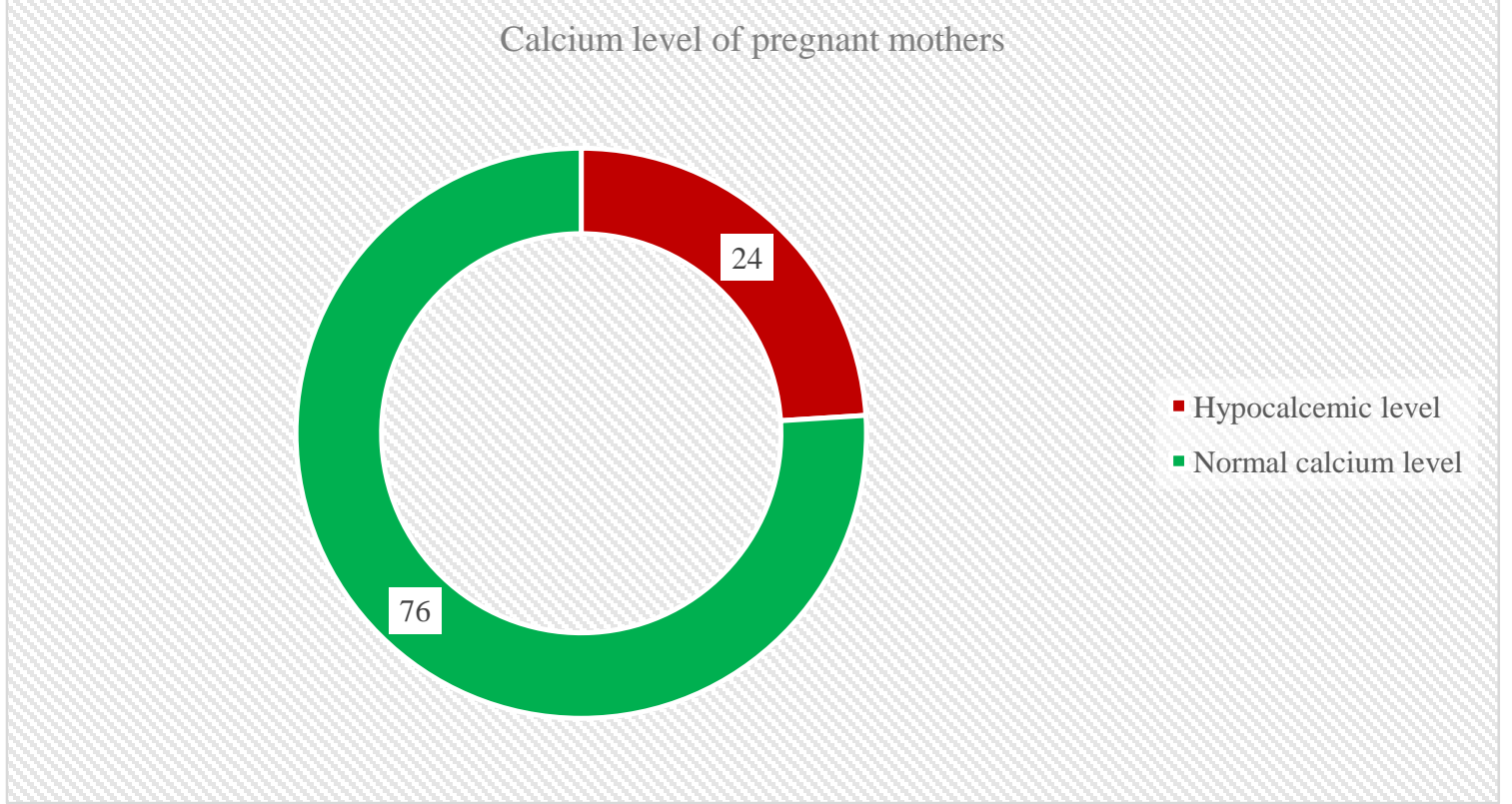

Figure: III Calcium Level of Pregnant Mothers (N=50)

Figure III showed out of 50 pregnant women total38(76\%) pregnant women's Calcium level were in between $8.5-10.5 \mathrm{mg} / \mathrm{dL}$ which refers to normal calcium level, and $12(24 \%)$ pregnant women's Calcium level werebelowtherangeof8.5$10.5 \mathrm{mg} / \mathrm{dL}$, which refers to Hypocalcemiaor Calcium deficiency. Total 38(76\%) pregnant women who has normal calcium level but still they need calcium complement or supplement in addition to the antenatal vitamins.

\section{Discussion}

All the collected statistics and surveys and related literature indicate that iron deficiency anemia, folate deficiency, and calcium deficiency during pregnancy is a community health hazard that distresses both emerging and advanced states, with serious human health, communal, and financial consequences. It has now become apparent that early recognition and proper diagnosis and management will play a crucial role in resolving the overall iron, folic acid, and $\mathrm{Ca}$ deficiency of pregnant mothers in poor countries such as Bangladesh. But because of our indifference and lack of knowledge, we do not feel much pride in gathering more and more data and sampling and disseminating awareness to avoid and handle. According to statistics, nearly half of Bangladeshi pregnant mothers have present haematological values that reflect anaemia, iron deficiency, folic acid deficiency, and vitamin $\mathrm{C}$ deficiency: effects on pregnancy outcome. Anemia during pregnancy is a nationwide health issue both in developed countries and in Bangladesh, which is a significant cause of co-morbidities and increasing death. Bangladesh is among the world's highest prevalence of stunting and micronutrient deficiency. Effects of anemia on the mother: Decreased cell-mediated immunity, reduced ability to withstand postpartum hemorrhage or bleeding, the strain of even uncomplicated labor may cause cardiac failure, predisposition to PIH and preterm labor due to associated malnutrition, reduced enjoyment of pregnancy and motherhood owing to fatigue, potential or possible threat to life. Effects to fetus/ baby: intrauterine hypoxia and growth retardation, prematurity, LBW, anemia a few months after birth due to poor stores, augmented danger of perinatal sickness, and death rate. ${ }^{14}$ Outcomes of Mild, Moderate, Severe Folic acid deficiency: miscarriage, poor growth in the womb, cleft lip and palate, preterm birth, small birth weight. ${ }^{15}$ Outcomes of Calcium deficiency during pregnancy: Pregnancy Induced Hypertension (PIH), fetal growth disorders, maternal mortality in developing regions, preeclampsia. ${ }^{16}$ Management of mild to severe Iron 
Deficiency Anemia (IDA) during pregnancy can include Accurate history of food intake and food habits, accurate history of medicine intake (if any), proper history of obstetric and social life, early detection of falling hemoglobin level, dietary advice with iron-enriched food and fruits, supplementary iron therapy, avoidance of frequent childbirth, adequate treatments to eradicate illnesses which may cause anemia. ${ }^{17}$ Management of Mild, Moderate, Severe Folic acid deficiency during pregnancy: For most women of reproductive age, the prescribed dosage is $400 \mu \mathrm{g}$ of folate per day. According to the Centers for Disease Control and Prevention (CDC), one can take folic acid daily for as a minimum of a month before getting pregnant and each day after giving birth. The CDC also advises, however, that folic acid be taken every day by all women of childbearing age. So, a pregnant mother would be okay to even start taking it sooner. ${ }^{15}$ Management of Mild, Moderate, Severe Folic acid deficiency during pregnancy: According to a new World Health Organization (WHO) recommendation, pregnant women in Bangladesh who consume 1.5 to $2.0 \mathrm{~g}$ of essential calcium per day from 20 weeks of pregnancy to the last day of pregnancy have a 14 percent lower risk of pre-eclampsia. ${ }^{18}$ Clinical guidelines: In Bangladesh, $\mathrm{Ca}$ be added to critical medicine lists. ${ }^{19}$ Global clinical recommendations should be revised in addition to the provision of $\mathrm{Ca}$ in antenatal care to incorporate an informative aspect in antenatal care as to signs of pre-eclampsia, to implement dietary guidance, and to improve the correct timing of the supplement. ${ }^{20}$ The Results of this present study indicate that- iron deficiency, folic acid deficiency, and calcium deficiency during pregnancy lead to, potential threats to the mothers such as miscarriage, pre-eclampsia, hemorrhage. pregnancy-induced hypertension (PIH), also brings out negative outcomes to the infants such as prematurity, low birth weight, growth retardation, cleft lip, cleft palate, and neural tube defects. Hence, our current slogan should be to increase awareness, proper diagnosis and management of iron, folic acid, calcium deficiency during pregnancy in order to fill the nutritional gap and to control the major causes of mortality and morbidity and poor maternal and fetal outcomes of pregnancy in Bangladesh We already came to know that about half of Bangladesh's population are undernourished. As we feel concerned about filling the nutrition gap and controlling the key causes of morbidity and death in childbearing women, we should give priority to widespread awareness, proper diagnosis, and management of iron, folic acid, $\mathrm{Ca}$ deficiency during pregnancy.

\section{Conclusion}

The results of this present study indicate that iron deficiency, folic acid deficiency, and calcium deficiency during pregnancy lead to potential threats to the mothers such as miscarriage, preeclampsia, hemorrhage, pregnancy-induced hypertension $(\mathrm{PIH})$, and also brings out negative outcomes to the infants such as prematurity, low birth weight, growth retardation, cleft lip, cleft palate, and neural tube defects too. Hence, our current slogan should be to increase awareness, proper diagnosis, and management of iron, folic acid, calcium deficiency during pregnancy in order to fill the nutritional gap and to control the major causes of mortality and morbidity and poor maternal and fetal outcomes of pregnancy in Bangladesh.

\section{References}

1. Grobman WA, Gersnoviez R, Landon MB, et al. Pregnancy outcomes for women with placenta previa in relation to the number of prior cesarean deliveries. Obstet Gynecol. 2007;110(6):1249-1255. doi:10.1097/01.AOG.0000292082.80566.c d.

2. Ananth CV, Demissie K, Smulian JC, et al. Placenta previa in singleton and twin births in the United States, 1989 through 1998: a comparison of risk factor profiles and associated conditions. Am J Obstet 
Gynecol.

$2003 ; 188(1): 275-281$.

doi:10.1067/mob.2003.10.

3. Cresswell J, Ronsmans C, Calvert C, et al. Prevalence of placenta praevia by world region: a systematic review and metaanalysis. Trop Med Int Health. 2013;18(6):712-724.

doi:10.1111/tmi.12100.

4. Fan D, Wu S, Wang W, et al. Prevalence of placenta previa among deliveries in Mainland China: a PRISMA-compliant systematic review and meta-analysis. Medicine. 2016;95(40): e5107. doi:10.1097/md.0000000000005107.

5. Butler E, Dashe J, Ramus R. Association between maternal serum alpha-fetoprotein and adverse outcomes in pregnancies with placenta previa. Obstet Gynecol. 2001;97(1):35-38. doi:10.1016/s00297844(00)01095-4.

6. Stoltzfus, R. J., L. Mullany, and R. E. Black. 2004. "Iron Deficiency Anemia." In Comparative Quantification of Health Risks: Global and Regional Burden of Disease Attributable to Selected Major Risk Factors. M.Ezzati, A. D. Lopez, A. Rodgers, and C. J. L. Murray, eds. Geneva: World Health Organization.

7. National Institute of Population Research and Training (NIPORT), Mitraand Associates, ICF International (2013) Bangladesh Demographic and Health Survey Report 2011.Dhaka, Bangladesh and Rockville, MD: NIPORT, Mitra and Associates, and ICF International.

8. Ahmed F, Prendiville N \& Narayan A (2016) Micronutrient deficiencies among children and women in Bangladesh: progress and challenges. J Nutr Sci5,e46.

9. National Institute of Population Research and Training, Mitraand Associates \& ICF International (2011) Bangladesh Demographic and Health Survey 2011. Dhakaand Calverton, MD: NIPORT, Mitra and Associates, and ICF International.
10. Public Health Nutrition: 3(4), 385 \pm 393385

Anaemiain Bangladesh: a review of prevalence and aetiology Faruk Ahmed* Institute of Nutrition and Food Science, University of Dhaka, Dhaka-1000, Bangladesh Submitted 23 August 1999: Accepted20March 2000

11. Fairlie FM, Sibai BM. Hypertensive diseases of pregnancy. In: Reece EA, ed. Medicine of the Fetus and Mother. Philadelphia, Pa: JB Lippincott; 1992:925942.7. Kaunitz AM, Hughes JM, Grimes DA, Smith JC, Rochat RW, Kafrissen ME. Causes of maternal mortality in the United States. ObstetGynecol.1985; 65:605-612.

12. Cunningham FG, MacDonald PC, Gant NF. Hypertensivedis. Orders in pregnancy. In: Williams Obstetrics. $18^{\text {th }}$ ed. Norwalk, Conn: Appleton \& Lange;1989:653-694.

13. Folate and cobalamin deficiencies and hyperhomocysteinemia in Bangladesh 2 Mary V Gamble, Habibul Ahsan, Xinhua Liu, Pam Factor-Litvak, Vesna Ilievski, Vesna Slavkovich, Faruque Parvez, and Joseph H Graziano Am J Clin Nutr.2005 June;81(6):1372-1377.

14. Botto LD, Mulinare J, Erickson JD. Domultivita Minor folicacid supplements reduce the risk for congenital heart defects? Evidence and gaps. Am J Med GenetA.2003;121A:95-101.

15. Bailey LB, Berry RJ. Folic acid supplementation and the occurrence of congenital heart defects, orofacialclefts, multiple births, and miscarriage. Am J Clin Nutr.2005; 81:1213S-1217S.

16. Huhta JC, Linask K, Bailey L. Recent advances in the prevention of congenital heart disease. Curr Opin Pediatr.2006; 18:484-489.

17. Ionescu-Ittu R, Marelli AJ, Mackie AS, Pilote L. Prevalence of severe congenital heart disease after folic acid fortification 
of grain products: time trend analysis in Quebec, Canada.BMJ.2009;338; b1673.

18. The impact of maternal iron deficiency and iron deficiency anemia onchild's health Noran M. Abu-Ouf, MBChB,MSc, Mohammed M. Jan, MBChB, FRCPC. J.Hopkins,"Folate-Deficiency Anemia".A. Almaghamsi, M. H. Almalki and B. M. Buhary," Hypocalcemiain Pregnancy: A Clinical Review Update," Oman Medical Journal, vol. 33, no. 6, pp. 453-462,2018.

19. L.K. Vricella, "Emerging understanding and measurement of plasma volume expansion in pregnancy, "Am $J$ Clin Nutr,vol.106,no.(Suppl),p.1620S-5S,2017.

20. G.WHO, "Calcium supplementation in pregnant women, "2013. a.M.T.I.A.I.A.R.C.K.C., N. Sheikh Mohammed Shariful Islam, "National drug policy reform for non communicable diseases in low-resource countries: an example from Bangladesh," Bull World Health Organ,vol.95,p.382-384,2017. 